\title{
Correction: Subarachnoid gadolinium following angiography-induced cortical blindness
}

Renard D, Chevalier C, Wacongne A. Subarachnoid gadolinium following angiography-induced cortical blindness. Practical Neurology 2018;18:240-41. doi: 10.1136/practneurol-2017-001873.

The title of this article was incorrectly shortened from 'Subarachnoid gadolinium following angiography-induced cortical blindness' to 'Transient cortical blindness following gadolinium contrast' during the editorial process. This has now been changed to the correct title online: 'Subarachnoid gadolinium following angiography-induced cortical blindness'.

Pract Neurol 2018;18:343. doi:10.1136/practneurol-2017-001873corr1

(A) Check for updates 